\title{
Synchronous Papillary Carcinoma in Thyroglossal Duct Cyst and Thyroid Gland Associated to Untreated Midline Cervical Cleft: A Case Report
}

\author{
Choukry K ${ }^{*}$, Khdim $M^{1}$, Beghdad $\mathrm{M}^{1}$, Choukry $S^{2}$, Rouadi $S^{1}$, Abada $\mathrm{R}^{1}$, Roubal $\mathrm{M}^{1}$ and Mahtar $\mathrm{M}^{1}$
}

${ }^{1}$ ENT Department, 20 August 1953 Hospital, 20’1953, CHU IBN ROCHD, Casablanca, Morocco

${ }^{2}$ Nuclear Medicine Department, CHU Ibn Rochd, Casablanca, Morocco

${ }^{*}$ Corresponding author: Choukry K, ENT Department, 20 August 1953 Hospital, 6 Rue Lahssen Elaarjoun, Casablanca, Morocco, Tel: 652035988, E-mail: karimchoukry@gmail.com

Citation: Choukry K, Khdim M, Beghdad M, Choukry S, Rouadi S, et al. (2019) Synchronous Papillary Carcinoma in Thyroglossal Duct Cyst and Thyroid Gland Associated to Untreated Midline Cervical Cleft: A Case Report. J Case Rep Stud 7(1): 108. doi: 10.15744/2348-9820.7.108

Received Date: May 28, 2018 Accepted Date: February 26, 2019 Published Date: February 28, 2019

\begin{abstract}
Introduction: Thyroglossal duct cyst is the most common anomaly in thyroid development. Majority is benign, but $1 \%$ may be malignant. Papillary carcinoma is the most frequent thyroid cancer. The synchronous occurrence of thyroglossal duct cyst and thyroid carcinoma is rare and the association with another congenital malformation is extremely rarer.

Case Report: A 41-year-old woman was referred to our department with complaints of a midline cervical abnormality. Clinicoradiological evaluation suggested a thyroglossal duct cyst with non-palpable nodules of thyroid gland and a midline cleft with fibrous cord. Sistrunk's procedure along with a total thyroidectomy associated to an excision and Z-plasty closure of this congenital cervical cleft were performed, followed by post-operative radioiodine ablation.

Discussion and Conclusion: Medline cervical cleft is a rare congenital malformation, which nonetheless has a classic presentation. It is often misdiagnosed as thyroglossal duct cyst. Co-existence of papillary carcinoma of thyroid gland and thyroglossal cyst is also a rare presentation and in this case, we discuss the clinical presentation, diagnosis, surgical treatment and draw attention to very rare case of patient with misdiagnosed CMCC.
\end{abstract}

Keywords: Thyroglossal Duct Cyst Carcinoma; Thyroid Carcinoma; Midline Cervical Cleft; Surgery

\section{Introduction}

Thyroglossal duct cyst (TGDC) is the most common anomaly in thyroid development. Thyroid gland descends from foramen caecum to a point below the thyroid cartilage. It leaves an epithelial tract known as thyroglossal tract. The tract disappears during $5^{\text {th }}$ to $10^{\text {th }}$ gestational week. Incomplete atrophy of tract forms the basis of origin of the cyst.

Development of carcinoma in a thyroglossal duct cyst remnant is uncommon; the first description by Brentano was in 1911 [1]. However, the synchronous occurrence of cancer in thyroglossal duct cyst and thyroid gland is extremely rare.

Congenital midline cervical cleft (CMCC) is a rare developmental abnormality of the ventral neck. It was first described by the German anatomist Luschka in 1848 [2]. It remains an uncommon malformation with approximately 200 cases reported in literature and not much case series [3]. It can be associated with cleft of lower lip or cleft tongue and rarely with a bronchogenic cyst or with respiratory epithelium, hemangiomata [4]. It can be often misdiagnosed as a TGDC.

We report a case of a 41 years old woman consulting in our ENT department, 20 August 1953 Hospital, Casablanca Morocco for synchronous occurrence of carcinoma in the thyroglossal duct cyst and thyroid gland associated to untreated midline cervical cleft.

\section{Case Report}

A 41 years old woman was referred to our department because of a midline cervical abnormality. She had midline skin lesion in the anterior part of the neck since birth with positive history of inflammation of the blind ending sinus with purulent discharge and swelling.

On examination, there was a linear cleft in the midline of the neck midway between the mandible and the sternal notch and covered by atrophic skin measuring $5 \mathrm{~cm}$ in length and approximately 5 to $10 \mathrm{~mm}$ wide (Figure 1). 


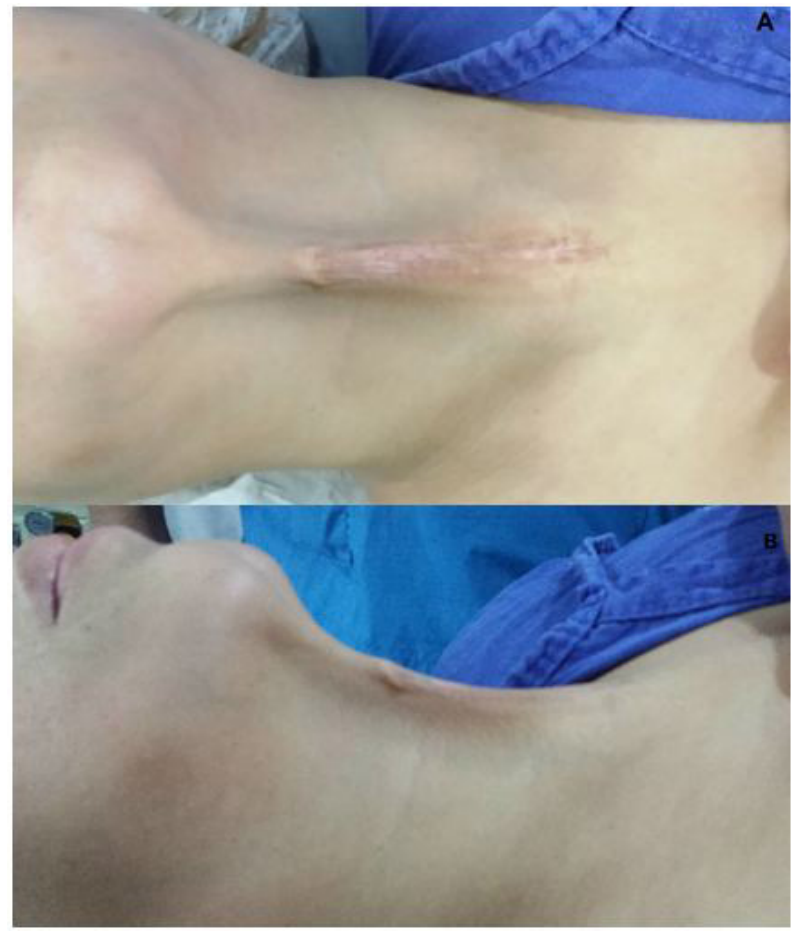

Figure 1: A 41 years old female with CMCC before surgery (A) front view; (B) profile view

Non-palpable nodules of the thyroid gland were found. On indirect laryngoscopy, the vocal cord movements were normal.

Routine hematology and blood biochemistry investigations were normal, as was the thyroid function tests. Ultrasonographic (USG) and computer tomography (CT) evaluation suggested the presence of an irregularly shaped complex TGDC measuring $5 \times 4 \mathrm{~cm}$ with solid and cystic components associated to distal blind ended fistula, fibrotic restricting chord and nipple like skin lesion. There was also a multiple nodules found in both lobes and isthmus of thyroid with fine calcification. There was no cervical lymphadenopathy (Figure 2). Ultrasound-guided fine-needle aspiration cytology (FNAC) from the solid area of the TGDC suggested papillary carcinoma.

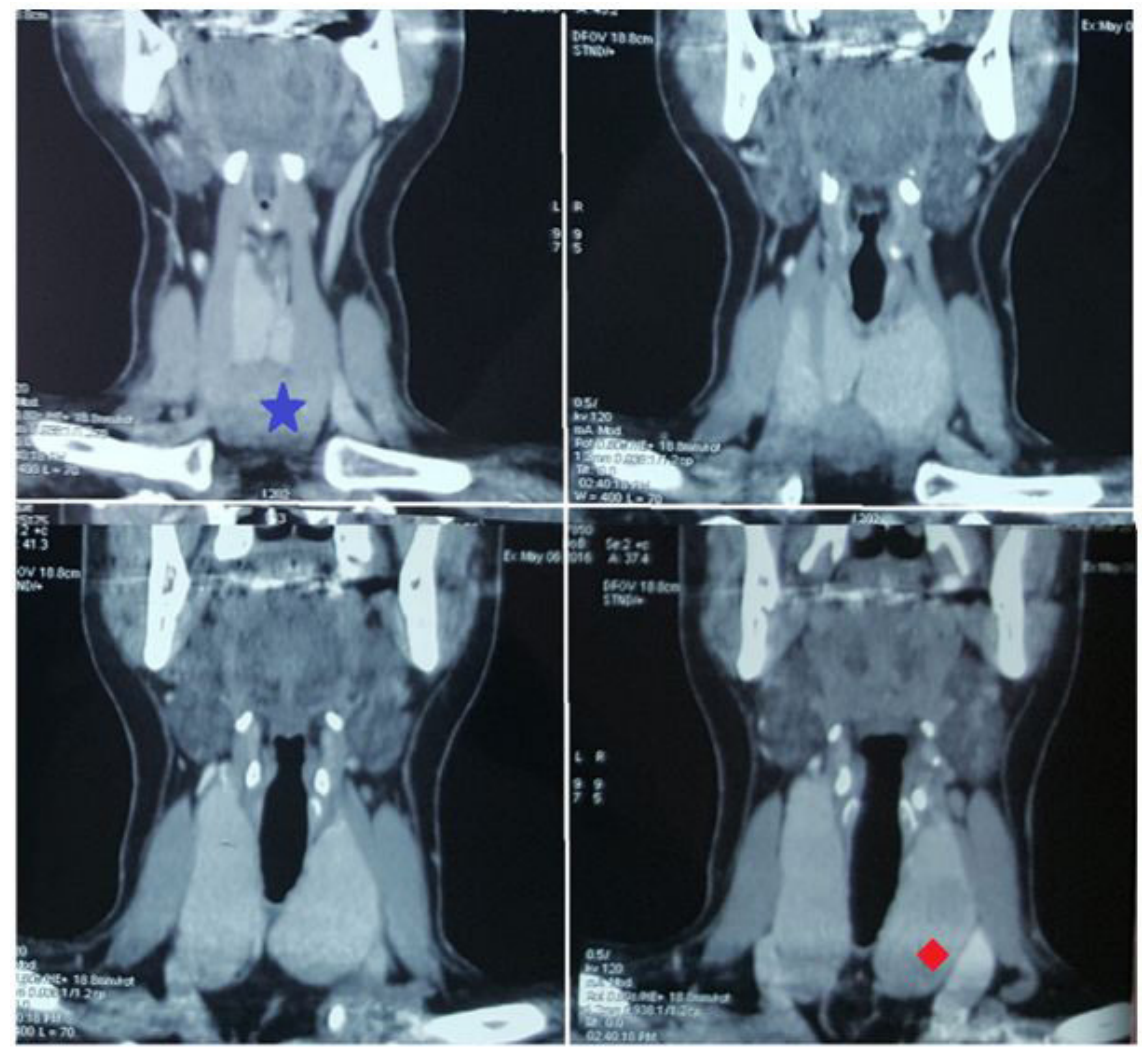

Figure 2: Contrast CT images showing the CMCC (the blue star) and a nodule in the left lobe of the thyroid gland (the red star) 
Sistrunk's procedure along with a total thyroidectomy and central compartment dissection was done under general anesthesia. For the midline cervical cleft, a surgical excision using elliptical incision and repair by Z-plasty was planned. The postoperative period was uneventful, and the patient was discharged on the third day.

Gross examination revealed TGDC, which was multiloculated and had solid and cystic areas (about $4 \mathrm{~cm}$ ). There was $1.5 \mathrm{~cm}, 1 \mathrm{~cm}$ nodules in the left lobe and $1 \mathrm{~cm}$ nodule in the right lobe of thyroid gland. A few lymph nodes were also identified. Microscopic diagnosis was multifocal papillary carcinoma of thyroid and thyroglossal cyst with no metastasis nodes. The excised lesion of CMCC was reported as skin that had a cleft lined by squamous epithelium in the center. The sinus tract was lined by pseudostratified ciliated columnar epithelium associated with rare seromucinous glands and chronic inflammation.

A low-dose radioiodine scanning (I131) was done, which showed minimal up take in the thyroid bed and no evidence of functioning distant metastasis. The patient underwent radioiodine ablation of the remnant thyroid tissue and was then put on thyroid-suppression drugs.

\section{Discussion}

TGDC is congenital cervical malformation due to abnormal persistence of the thyroglossal tract residue of the migration of the thyroid gland from the base of the tongue to its definitive anatomical localization $[5,6]$. Majority is benign, but $1 \%$ may be malignant $[7,8]$. They occur mainly in adults towards the fourth decade [5,9]. Carcinomas arising in the thyroglossal duct cysts are rare, accounting only for about $0.7 \%$ to $1.5 \%$ of all thyroglossal duct cysts [10]. Synchronous occurrence of thyroglossal duct cyst and thyroid carcinoma is even rarer. Thyroid papillary carcinoma is the most common type (80\%), followed by mixed papillary or follicular carcinoma (7\%), squamous cell carcinoma (5\%), follicular and adenocarcinoma (1,7\%) and anaplastic carcinoma $(0.9 \%)[10]$. The origin of thyroid cancer in a thyroglossal duct cyst is discussed. Some believe that they arise de novo from islands of normal thyroid tissue found in thyroglossal duct remnants. Others suggest that they are probably metastases from a thyroid carcinoma through a patent thyroglossal duct [1] (Figure 3).

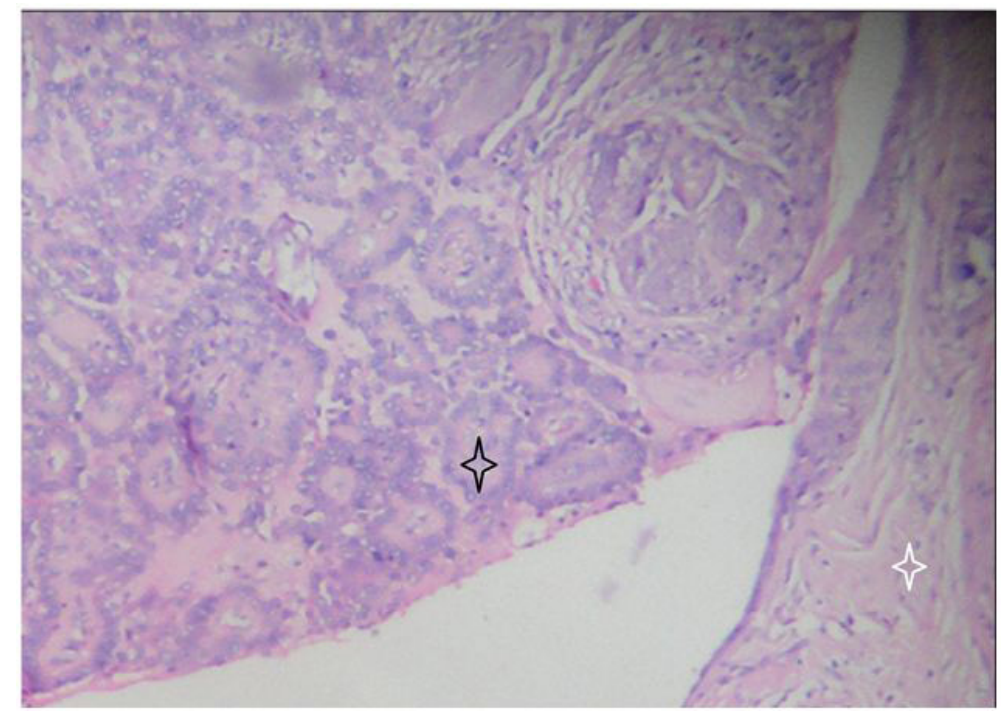

Figure 3: A histopathological figure of papillary carcinoma $40 \times$ optical zoom The "white star" showing normal cyst wall lining

The "black star" indicating papillary carcinoma of the thyroglossal cyst

Malignancy should be suspected in midline cysts of the neck, which are irregular, hard, fixed, or associated with significant neck nodes [10]. The clinical presentation is often similar to a benign cyst, and the diagnosis of malignancy is usually obtained postoperatively from histopathology reports. This leads to difficulties in planning appropriate surgical treatment in 1 stage. Fineneedle aspiration cytology (FNAC) has a 50\% chance of achieving a preoperative diagnosis. Scintigraphy may help differentiating a partially descended thyroid from a TGDC and identifying cold nodules in the thyroid gland. USG and CT help characterize the extent, presence of solid components, calcification, co-existing thyroid nodules, and cervical lymphadenopathy [11].

When malignant TGDC is preoperatively diagnosed, pre-operative imaging and careful intra-operative evaluation of thyroid gland is performed to rule out clinically occult neoplastic nodules [9]. Presence of synchronous thyroid nodules warrants total thyroidectomy in addition to the Sistrunk's operation. But in majority of cases, diagnosis of malignant TGDC is made postoperatively. If histopathology of cyst is negative or shows low risk malignancy features like microscopic focus less than $1 \mathrm{~cm}$ without cyst wall invasion, follow up alone is adequate $[9,11]$. If there are high risks features like a neoplastic focus more than $1 \mathrm{~cm}$ or cyst wall invasion, then a total thyroidectomy is recommended as these lesions are aggressive. 
Further, total thyroidectomy allows long-term monitoring of thyroglobulin and I131 studies [9]. There is no role for prophylactic lateral neck dissection [13]. Postoperative management of synchronous malignant TGDC and thyroid carcinoma is in line with the guidelines adopted for the management if differentiated thyroid cancer [11].

CMCC is rare anomaly of anterior neck and very often followed by misdiagnosis. Its origin is not clearly resolved. It is assumed of impaired fusion of $1^{\text {st }}$ and $2^{\text {nd }}$ branchial arches as the most acceptable explaining in $3^{\text {th }}-4^{\text {th }}$ week of embryogenesis [3]. It can be associated with other congenital lesions as described in our case report. Most of cases have been associated with cleft sternum or ectopia with intracardiac anomalies [4].

The majority of CMCC are diagnosed clinically at birth and treated in the first months of life. However, it can be misdiagnosed as thyroglossal duct cyst. The lesion varies includes nipple-like skin appendix in the superior portion, cleft in the middle portion and sinus tract in the inferior portion [12]. The differential diagnosis includes many congenital anomalies (Table 1), especially branchial, thyroglossal and chondrobranchial tissues. Although CMCC is easily differentiated by its typical presentation, imaging studies are needed (CT scan, MRI) [13].

\begin{tabular}{|c|}
\hline Thyroglossal duct cyst \\
\hline Dermoid cyst \\
\hline Branchial cleft cyst \\
\hline Thyroglossal fistula \\
\hline Bronchogenic cyst \\
\hline Epidermal inclusion cyst \\
\hline Fibroepithelial polyp \\
\hline
\end{tabular}

Table 1: Differential diagnosis of the CMCC

Untreated CMCC may cause neck contractures and deformations of mandibula and sternum. The purpose of early surgery is to avoid cicatrical contractures and mandibular deformities [14]. Surgical golden standard is complete excision of pathological tissue with skin, platysma, fibrotic cord and the multiple or simple Z-plasty, which are believed to help avoid cicatrical contractures and vertical scar [14].

Our case showed that there is a possibility that more than one anomaly can be seen in same patient simultaneously, so that we should always keep in mind and look for a possible associated or concurrent lesion.

\section{Conclusion}

Thyroglossal duct cyst carcinoma is unusual, also synchronous occurrence of cancer in thyroglossal duct cyst and thyroid gland is even rarer. The association between CMCC and TGDC is extremely rare. The CMCC can be misdiagnosed as thyroglossal duct cyst. The suitable time of CMCC surgery is in the first months of life.

\section{References}

1. Cherian MP, Nair B, Thomas S, Somanathan T, Sebastian P (2016) Synchronous papillary carcinoma in thyroglossal Duct cyst and thyroid gland: case report and review of literature. Head Neck 31: 1387-91.

2. Achard S, Leroy X, Fayoux P (2016) Congenital midline cervical cleft: A retrospective case series of 8 children. Int J Pediatr Otorhinolaryngol 81: 60-4.

3. Puscas L (2015) Midline cervical cleft: review of an uncommon entity. Int J Pediatr 10.1155/2015/209418.

4. Macaj M, Jovankovicova A, Jakubikova J, Koller J (2016) A case of untreated midline cervical cleft associated with congenital heart defect. Case Studies in Surgery 10.5430/css.v2n1p60.

5. Ghfir I, Ouboukdir R, M'Hamdi F, Ben Rais Aouad N (2010) Degenerated thyroglossal duct cyst revealing a multifocal micropapillary thyroid carcinoma. J Mednuc 34: 29-33.

6. Kim WJ, Souillard R, Brandwein MS, Lawson W, Som PM (2005) Follicular adenoma in a juxttathyroidal thyroglossal duct cyst with papillary carcinoma in the adjacent thyroid gland. Am J Otolaryngol 26: 348-50.

7. Miccoli P, Minuto MN, Galleri D, Puccini M, Berti P (2004) Extend of surgery in TGDC carcinoma reflections on a series of 18 cases. Thyroid 14: 121-3.

8. Luna-Ortiz K, Hurtado-Lopez LM, Valderrama-Landaeta JL, Ruiz-Vega A (2004) Thyroglossal duct cyst with papillary carcinoma: What must be done. Thyroid 14: 363-6.

9. Tharmabala M, Kanthan R (2013) Incidental thyroid papillary carcinoma in a thyroglossal duct cyst management dilemmas. Int J Surg Case Rep 4: 58-61.

10. Senthilkumar R, Neville JF, Aravind R (2013) Malignant thyroglossal duct cyst with synchronous occult thyroid gland papillary carcinoma. Ind J Endocrinol Metab 17: 936-8.

11. Park MH, Yoon JH, Jegal YJ, Lee JS (2010) Papillary thyroglossal duct cyst carcinoma with synchronous occult papillary thyroid microcarcinoma. Yonsei Med J 51: 609-11.

12. Hirokawa S, Hideyuki U, Okami H, Tsukada K, Futatani T, et al. (2003) Congenital midline cervical cleft 101 case of congenital midline cervical cleft with congenital heart disease. J Pediatr Surg 38: 1099-101.

13. Genc A, Taneli C, Arslan O, Dağlar Z, Mir E (2002) Congenital midline cervical cleft: a rare embryopathogenic disorder. Eur J Plast Surg 25: 29-31.

14. McInnes CW, Benson AD, Verchere CG, Ludemann JP, Arneja JS (2012) Management of Congenital Midline Cervical Cleft. J Craniofac Surg 23: e36-8. 


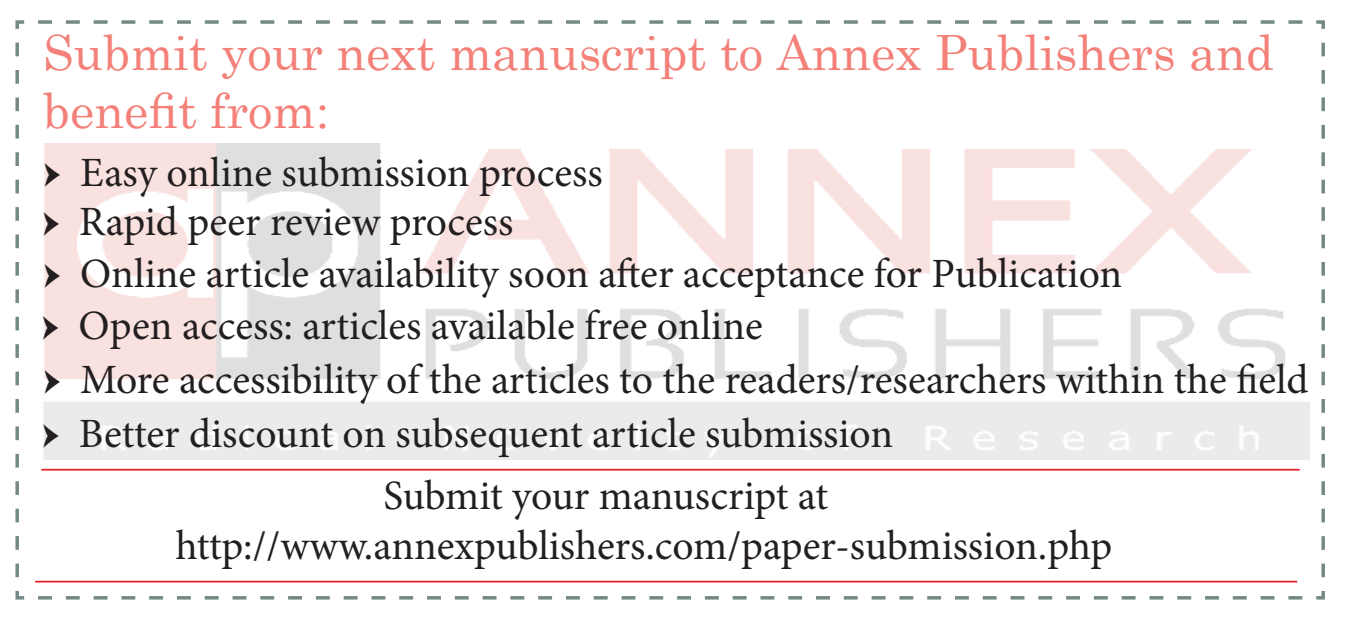

